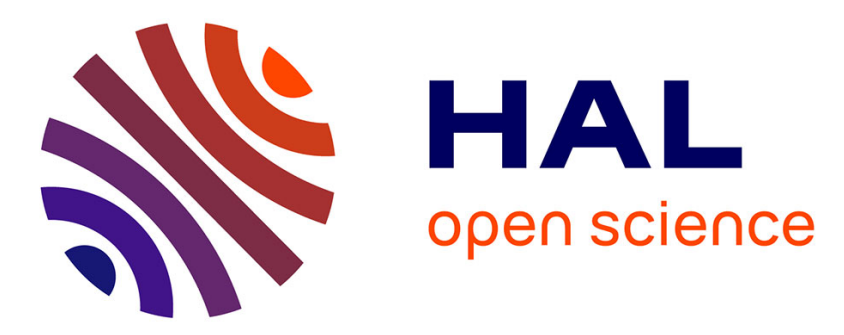

\title{
AUTOMATIC SYSTEM FOR MEASUREMENTS OF INTERNAL FRICTION AND ELASTIC MODULI
}

\author{
M. Weller, E. Török
}

\section{To cite this version:}

M. Weller, E. Török. AUTOMATIC SYSTEM FOR MEASUREMENTS OF INTERNAL FRICTION AND ELASTIC MODULI. Journal de Physique Colloques, 1987, 48 (C8), pp.C8-371-C8-376. 10.1051/jphyscol:1987855 . jpa-00227159

\section{HAL Id: jpa-00227159 https://hal.science/jpa-00227159}

Submitted on 1 Jan 1987

HAL is a multi-disciplinary open access archive for the deposit and dissemination of scientific research documents, whether they are published or not. The documents may come from teaching and research institutions in France or abroad, or from public or private research centers.
L'archive ouverte pluridisciplinaire $\mathbf{H A L}$, est destinée au dépôt et à la diffusion de documents scientifiques de niveau recherche, publiés ou non, émanant des établissements d'enseignement et de recherche français ou étrangers, des laboratoires publics ou privés. 


\title{
AUTOMATIC SYSTEM FOR MEASUREMENTS OF INTERNAL FRICTION AND ELASTIC MODULI
}

\author{
M. WELLER and E. TÖRÖK* \\ Max-Planck-Institut für Metallforschung, Institut für \\ Werkstoffwissenschaften, D-7000 stuttgart, F.R.G. \\ * Institut Straumann AG, CH-4437 waldenburg. Switzerland
}

\begin{abstract}
Résumé - On a développé un système universel et automatique, avec un barreau víbrant en résonance, qui est controlé par un microordinateur, pour mésurer le frottement interne et les modules d'élasticitè dans une gamme de températures étendues de $10 \mathrm{~K}$ à $1300 \mathrm{~K}$. La décroissance des oscillations ( $100 \mathrm{~Hz}-$ $30 \mathrm{KHz}$ ) est détectêe par une méthode électrostatique avec modulation en fréquence et stockèe en appliquant une conversion A/D (12 bit) rapide. Cela rend possibje des mésures de frottement interne dans une gamme de $Q^{-1}=10^{-6}$ jusqu'à $10^{-1}$. Des exemples expérimentaux sont présentés pour montrer la puissance et l'universalité du.système.

Abstract - A versatile computer controlled automatic resonant bar system has been developed for measurement of internal friction and elastic moduli in a wide temperature range of $10 \mathrm{~K}$ to $1300 \mathrm{~K}$. The decaying oscillations ( $100 \mathrm{~Hz}$ to $30 \mathrm{KHz}$ ) are detected electrostatically by the frequency modulation technique and stored using high speed buffered 12 Bit $A / D$ conversion enabling internal friction to be measured in the range $0^{-1}=10^{-6}$ to $10^{-1}$. Examples of measurement are presented to show the capability and versatility of the system.
\end{abstract}

\section{I - INTRODUCTION}

The resonant bar technique is well known for a long time as a classical method for the investigation of the elastic properties of solids. The resonance frequency of a sample excited to mechanical vibrations is one of its eigenfrequencies. These are determined only by the mode of oscillation (flexural, torsional or longitudinal), the appropriate elastic moduli, and the dimensions and density of the sample. By exciting the sample to distinct oscillations (at the different temperatures) the corresponding elastic moduli (Young's modulus $E$ or shear modulus $G$ ) are obtained. Simultaneously the internal friction may be determined from the decay of the amplitude of the eigenvibrations. A variety of different types of apparatus is described in literature (see e.g. /1-3/).

In this paper we describe a versatile experimental set up which is especially characterized by a wide temperature range (10K to 1300K), high vacuum, and a variety of sample geometries (bars, wires or ribbons) which may be used. Also the newly developed, automatic computer controlled measuring system allows rapid and precise measurements of frequency and internal friction in a wide range $\left(Q^{-1}=10^{-6}\right.$ up to $\left.10^{-1}\right)$.

II - MECHANICAL PART

1.) Sample holder. - Usually specimens with 40 or $50 \mathrm{~mm}$ length and rectangular cross section $(5 \times 1 \mathrm{~mm})$ or wires with $1 \mathrm{~mm}$ diameter are excited to flexural vibrations in the free-free mode. This is shown schematically in Fig. 1 (front view) and Fig. 2 (lower part, side view). The sample, mounted horizontally, is supported directly at the nodes of oscillation by two thin wires $\left(W_{1}, W_{2}\right)$ of $0.3 \mathrm{~mm}$ diameter, one nickel 
and the other chromel acting simultaneously (together with the sample) as the thermocouple for temperature measurement. Each wire is guided through rollers mounted on a stainless steel frame (A1,A2) (Fig. 1 and 2) thus forming a loop around the sample. One end is electrically isolated and pulled up with a spring, the other end goes through plate B. The distance, a, between the two frames (A1) and (A2) can be adjusted according to the sample length, $Z$, in order to match the distance of the nodes of oscillation.

A special sample holder is used for thin ribbons. The sample is clamped only at one end between two jaws which are mounted in part Al and thus oscillates as a cantilever beam (vibrating reed). In this case temperature is measured by inserting another thermocouple (Philips thermocoax) into the jaws close to the sample.

2.) A view of the total mechanical arrangement is shown schematically in Fig. 2 . The sample holder from Fig. 1 (P, A1, A2) is connected by four long rods $\mathrm{R}$ with plate B resting on the basal cube $C$ which is mounted on a base plate $B P$. This vertical arrangement enables different tubes with furnaces or cryostats, to be positioned below the cube $C$ depending on the required temperature range.

The standard arrangement as shown in Fig. 2 is designed for temperatures between $77 \mathrm{~K}$ and about $850 \mathrm{~K}$. The sample holder is surrounded by the heating cage $\mathrm{H}$ (Philips thermocoax heater). S1 and S2 are heat shields containing holes for the supporting rods $R$, the thermocouple wires $W 1$ and $W 2$ and the carrier rod of the excitation electrode $E$. The entire assembly is surrounded by a double walled tube (T) with $72 \mathrm{~mm}$ inside diameter and $750 \mathrm{~mm}$ length which is mounted from below to the basal plate BP at flange $F$. This tube may be evacuated (for heating to higher temperatures) or filled with exchange gas $\left(\mathrm{N}_{2}, \mathrm{He}\right)$ when immersed into a dewar with liquid nitrogen for lowering the temperature to $77 \mathrm{~K}$. The electrode rod, E, (isolated at part I) may be moved up and down with the aid of micrometer $M$ which is connected with the aid of a clutch and gear to the DC motor D.

For operation at Zower temperatures the heater $H$ and the outer parts of the shields $S 1, S 2$ are demounted. The surrounding tube $T$ is then replaced by a liquid helium cryos tat with $63 \mathrm{~mm}$ inside diameter (Leybold Heraeus $\mathrm{GmbH}$, Köln) enabling temperatures from about $10 \mathrm{~K}$ up to $650 \mathrm{~K}$.

A modified mechanical set up is used for high-temperature measurements in the range from RT up to $1300 \mathrm{~K}$. The sample holder $(P, A 1, A 2)$ and envelope tube $T$ are constructed from high temperature materials (Inconel), and parts of the supporting rods from aluminium oxide. Instead of $\mathrm{Ni} / \mathrm{NiCr}$, Pt/PtRh thermocouple wires are used. Heating occurs by a furnace (Kanthal Co., $2 \mathrm{KW}$ ) positioned around the lower part of tube T. Radiation fins are positioned between plate BP and the furnace.

In al1 cases measurements are carried out in a vacuum of $10^{-5}$ to $10^{-6}$ mbar, which is also required for the high voltage excitation.

\section{III - EXCITATION AND MEASURING SYSTEM}

The basic principle of the system is represented schematically in Fig. 3. It is subdivided into the excitation and detection system (upper part) and the computer controlled measuring system (lower part).

Excitation and detection of the sample oscillations is based on the well known electrostatic principle (see e.g. /1-3/). A single electrode is used for excitation and pick up of the osciliations as was used by Bordoni $/ 4 /$, Pare $/ 5 /$ and others 16-8/. Amplitude detection occurs by using the frequency modulation (FM) and demodulation technique. The distance between the sample and the electrode varies with the change in temperature. This is kept constant by the geared DC motor driving a micrometer head connected to the electrode rod (see Fig. 2).

The vibrations are excited and maintained constant in a feed back system by an $A C$ voltage in the range of 50-300 V, which is superimposed on a DC polarisation voltage $(150-450 \mathrm{~V})$. Particular modes of oscillation (fundamental vibration or higher tones) may be selected with the aid of a newly designed Chebyschev bandpass filter system with selectable centre frequency and bandwidth. Torsion oscillations of samples 
(with rectangular cross section) may be excited by placing the electrode displaced sideways with respect to the main sample axis.

The measuring and control system is based on the standard IEEE 488-1978 (HP-IB) interface bus with a Hewlett-Packard (HP) series 200 computer as controller and with the usual peripheral units (floppy disc, plotter and printer).

The thermovoltage of the sample is monitored by a standard (high resolution) DVM (HP 3478A). Since the sample is supported directly by the thermocouple wires (W1,W2) the temperature is measured instantaneously at the sample. The temperatures $T$ are calculated by comparison with a calibrated $\mathrm{Pt}-100$ resistance and (corresponding) polynomial fits (accuracy $T= \pm 0.1$ to $0.3 \mathrm{~K}$, depending on the temperature range). Temperature variation and control occurs by a temperature controller TC 8101 with power supply (Telbit GmbH, Stuttgart).

The frequency $f$ is measured with an universal counter (Philis PM 6654) with a temperature stabilized quartz crystal. The resolution in the $\mathrm{kHz}-$ ranges is $\Delta \mathrm{f} / \mathrm{f} \approx 10^{-7}$. The internal friction, $Q^{-1}$, is determined from the freely decaying amplitudes after switching off the excitation amplifier with a relay switch which is controlled by the universal interface (UI 488, Telbit).

The decaying oscilzation is monitored with the aid of a rapid $A / D$ converter with 12-bit ( $31 / 2$ digit) resolution. For this purpgse we use a HP $6942 \mathrm{~A}$ multiprogrammer with a $69751 \mathrm{~A}$ plug in card enabling up to $3.3 \times 10^{4}$ readings per second and 4K-byte buffered memory (500 kHz and $64 \mathrm{kByte}$ optiona1). Other technical solutions to digitize the amplitude decay are conceivable (e.g. transient recorders or storage oscilloscopes). The advantage of our system is that it is computer controlled and may thus be tailored to widely differing situations by software programming: (i) Digitizing of the decay curves may be adapted to the level of damping. High damping requires a high reading rate within a small number of oscillations, for low damping just the reverse is necessary. (ii) The digitized and stored decay data are accessible to multiple mathematical treatments, fitting procedures etc. to determine the internal friction, $Q^{-1}$, of the decaying oscillation, or $i$ ts amplitude dependence.

Fig. 4 shows as an example the amplitude decay for a sample with high damping ( $f=$ $3.06 \mathrm{kHz}$ ). (It relates to the peak damping in Fig. 5 at $\approx 480 \mathrm{~K}, \mathrm{Q}^{-1}=1.6 \times 10^{-2}$ ). The internal friction is determined by integrating over every positive and negative halfperiod of the oscillation followed by fit of an exponential decay. This method al lows the internal friction within a wide range from up to $Q^{-1}=10^{-1}$ down to $10^{-6}$ to be determined with high accuracy. Fig. 4 shows additionally a Fourier transform (FFT) of the decaying oscillation.

The elastic moduli of the sample are obtained from the theory of elastic vibrations (Bernoulli-Euler and Timoshenko beam theory). From flexural eigenvibrations of (isotropic) rectangular bars, with thickness $h$, width b length $l$, and density $o$, Young's modulus, $E$, is obtained from the frequency of the fundamental mode, $f_{1}$, as given by Spinner and Tefft /9/

$$
E=0.94642 \rho 2^{4} / h^{2}\left(f_{1}\right)^{2} F
$$

The correction factor $F$ depends on the shape and is given for a Poisson ratio of $v$ $=0.3 \mathrm{as}$

$$
\mathrm{F}=1+6.596(\mathrm{~h} / 2)^{2}+\ldots
$$

For our standard sample dimensions, $b=5 \mathrm{~mm}, \mathrm{~h}=1 \mathrm{~mm}$ the correction factor is $F=1.0041$ for $l=40 \mathrm{~mm}$, and $F=1.0026$ for $l=50 \mathrm{~mm}$. The nodes are positioned at $0.224 Z$ and $0.776 Z$.

From flexural vibrations of cylindrical specimens with diameter $d, E$ is obtained from the frequency of the first mode $19 \%$.

$$
E=1.261886 \rho l^{4} / h^{2}\left(f_{1}\right)^{2} F_{1}
$$

The correction factor is calculated in $/ 9 /$ (with $d=1 \mathrm{~mm}$ and $v=0.3: F_{1}=1.0021$ for $Z=50 \mathrm{~mm} ; F_{1}=1.0036$ for $Z=40 \mathrm{~mm}$ ). 
The shear modulus, $G$, of rectangular bars is derived from torsional resonant frequencies, $f_{n}$, as $/ 9 /$

$$
G=\left(2 \imath f_{n} / n\right)^{2} R
$$

The shape factor may be approximated for $h / b \ll 1$ as $/ 9,10 /$

$$
R=\left(1+(b / h)^{2}\right) /(4-2.521 \mathrm{~h} / \mathrm{b})
$$

(For $b=5 \mathrm{~mm}$ and $h=1 \mathrm{~mm}, R=7.437$ ). The second torsion mode $(n=2)$ has $i$ ts node positions at 0.252 and $0.75 i$, i.e. close to the node positions for the fundamental flexure mode. It may thus be excited in our apparatus with the same wire positions by sideward displacement of the electrode.

For further informations on elastic vibration of bars such as vibration frequencies, node positions, correction factors etc. we refer, e.g., to $/ 1,3,9,11 /$.

\section{IV - EXPERIMENTAL EXAMPLES}

Figures 5 to 7 illustrate the applicability and versatility of the apparatus.

Fig. 5 shows the temperature dependence of the internal friction, $Q^{-1}$, and Young's modulus, $E$, for a ceramic sample, $\mathrm{ZrO}_{2}$ doped with $3 \% \mathrm{Y}_{2} \mathrm{O}_{3}$ (Y-TZP), from ref. /12/. The sample with dimensions of $40 \times 5 \times 1 \mathrm{~mm}$ was oscillating in flexure (fundamental mode, $f=3.06 \mathrm{kHz}$ ). One side was covered with silver paint. E was calculated with eq.(1).

Fig. 6 shows measurements with a thin amorphous $\mathrm{Ni}_{35} \mathrm{Ti}_{65}$ ribbon about $30 \mu$ thick and $3 \mathrm{~mm}$ wide which was clamped at one end and oscillating as a cantilever beam with a free length of $7 \mathrm{~mm}$. The peak at $240 \mathrm{~K}$ is correlated with the presence of hydrogen $/ 13 /$.

Finally, Fig. 7 demonstrates measurements up to $1273 \mathrm{~K}$ obtained with the high temperature sample holder obtained on a stainless steel (316L) sample /14/. Two subsequent runs are shown in Fig. 7a for the internal friction, in Fig. 7b, for the elastic moduli, E and G. In the first run of Fig. $7 \mathrm{a}$, the peak at $170 \mathrm{~K}$ is interpreted as a Bordoni type relaxation, the second one at $340 \mathrm{~K}$ is attributed to interstitial solute atoms, probabty carbon /14/.

Acknowledgements are due to $\mathrm{Dr}$. J. Diehl for his support and continuous interest and Dr. B. Purniah for helpfuT and valuable discussions. The technical assistance of Mr. B. Rahn is gratefully acknowledged.

\section{REFERENCES}

/1/ A.S. Nowick, B.S. Berry, Anelastic Relaxation in Crystalline Solids, Academic Press, New York, 1972

12/ R. de Batist, Internal Friction of Structural Defects in Solids, North-Holland, Amsterdam, New York, 1972.

/3/ D.N. Beshers, Techniques of Metals Research, Vol.VIII, Part 2 (R.F. Bunshah ed.), J. Wiley, New York, 1976, p. 529.

14/ P.G. Bordoni, I7 Nuovo Cimento 4, 177 (1947).

/5/ V.K. Pare, Thesis, Cornell University, Ithaca, N.Y., 1958.

16/ P.A. Grandchamp and R.C. Fornerod, J.Phys.E, 3, 219 (1970).

17/ G. Fantozzi, Thèse, L'Université Claude Bernard de Lyon (1971).

18/ G. Hausch and E. Török, phys.stat.sol.(a) 40, 55 (1977).

19/ S. Spinner and W.E. Tefft., Amer. Soc. Testing Mater. 61, 1221 (1961).

$/ 10 /$ G. Pickett, Amer. Soc. Testing Mater. 45, 846 (1945).

111/ H.E. Rosinger, I.G. Ritchie and A.J. Shililinglaw, Atomic Energy of Canada Ltd., Report AECL-5114, 1976.

112/ M. Weller and H. Schubert, J.Amer.Ceram.Soc. 69, 573 (1986).

/13/ U. Stolz, M. Weller and R. Kirchheim, Scripta Met. 20, 1361 (1986).

$114 /$ J.P. Simpson, E. Török, Festschrift Dr. F. Straumann, Materialwissenschaft und Uhrentechnik, Ski, Chirurgie und Zahnmedizin, Institut Straumann, 1985. 


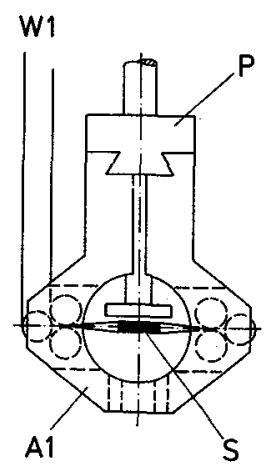

Fig. 1 - Sample holder

Fig. 2 - Mechanical part (schematically).

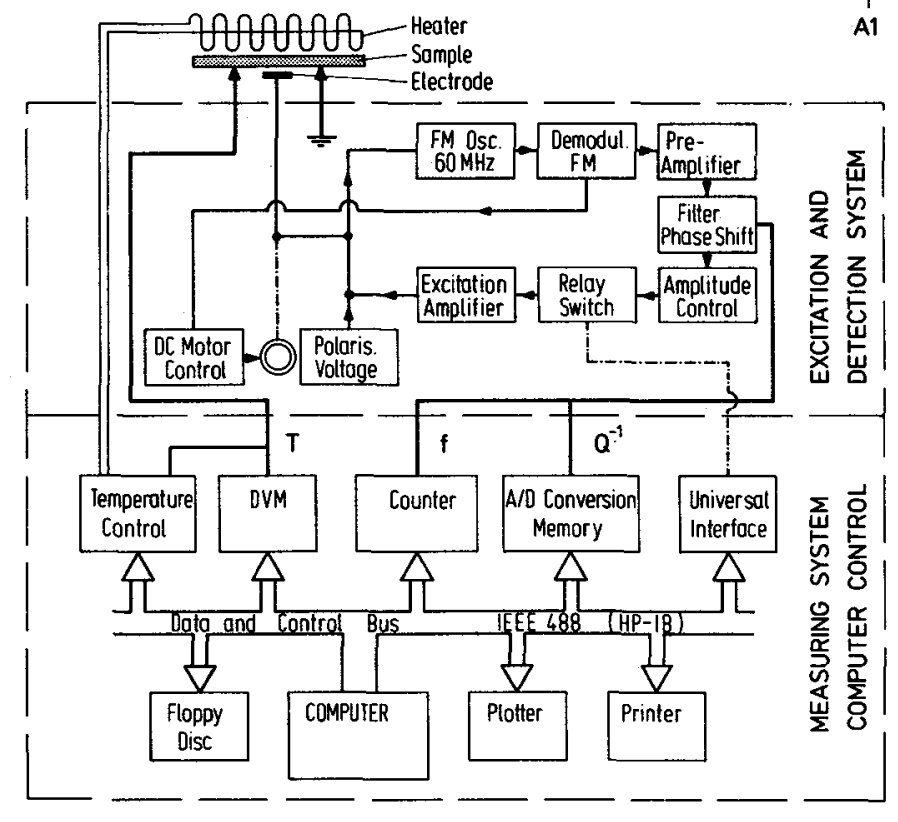

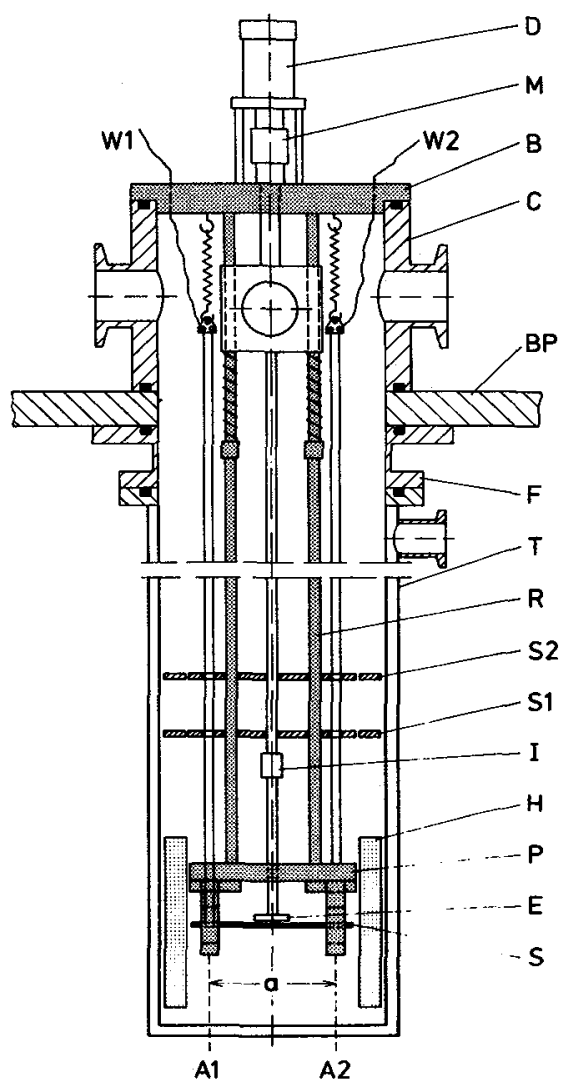

Fig. 3 - Block diagram of the excitation and measuring system. 

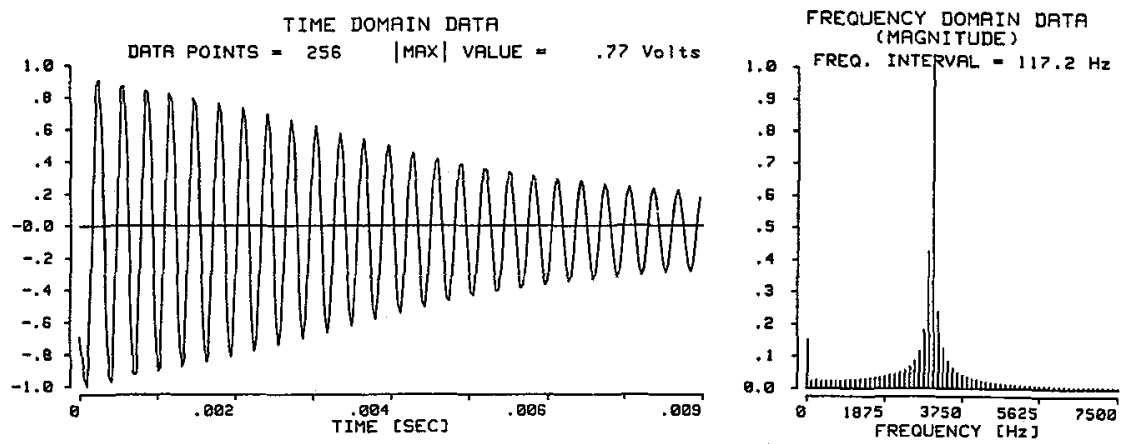

Fig. 4 - Amplitude decay and FFT for a sample vibrating at $3.06 \mathrm{kHz}$.

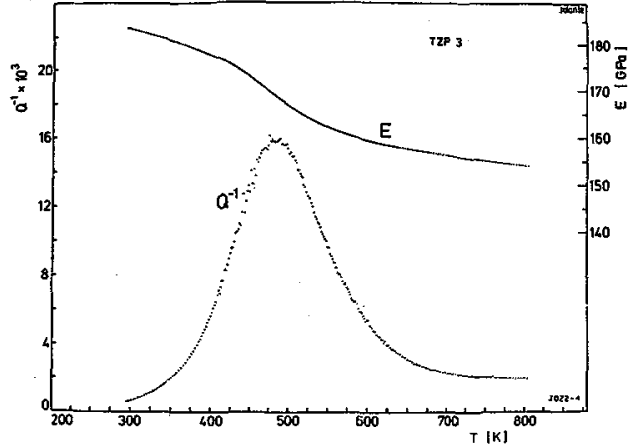

Fig. $5-Q^{-1}$ and $E$ vs. temperature for $\mathrm{ZrO}_{2}-\mathrm{Y}_{2} \mathrm{O}_{3}$ ceramics $(f \approx 3.06 \mathrm{kHz}$ ).

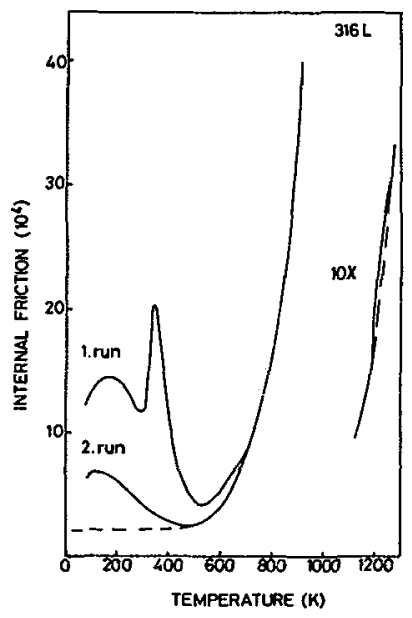

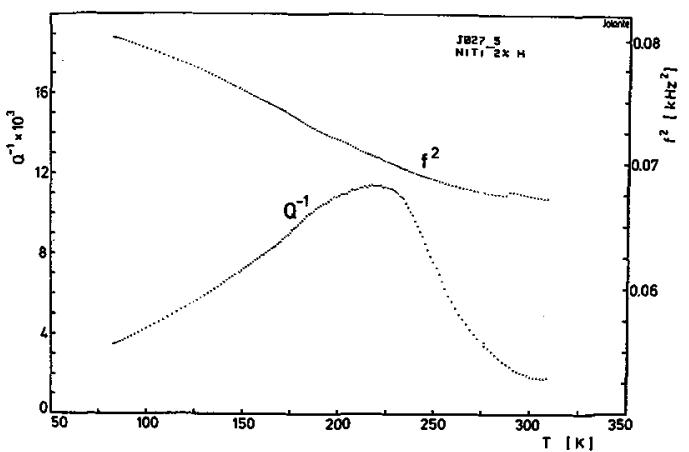

Fig. $6-Q^{-1}$ and $f^{2}$ vs. temperature for an amorphous $\mathrm{Ni}_{35}{ }^{\mathrm{Ti}} 65$ ribbon. $(\mathrm{f} \approx 270 \mathrm{~Hz}$ ).

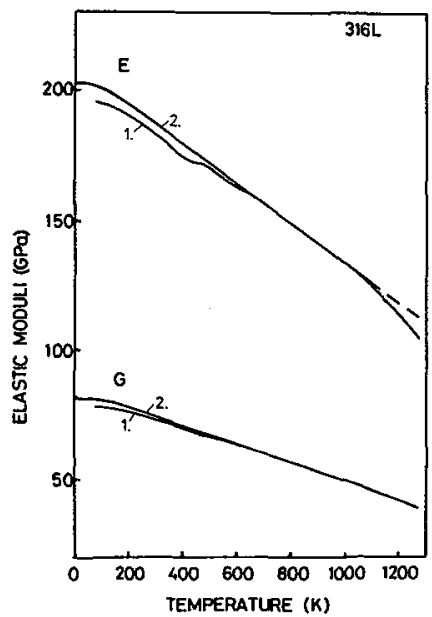

Fig. 7 - Temperature dependence of the internal friction (a) and the elastic modui $i(E, G)(b)$ for a staintess steel sample. 